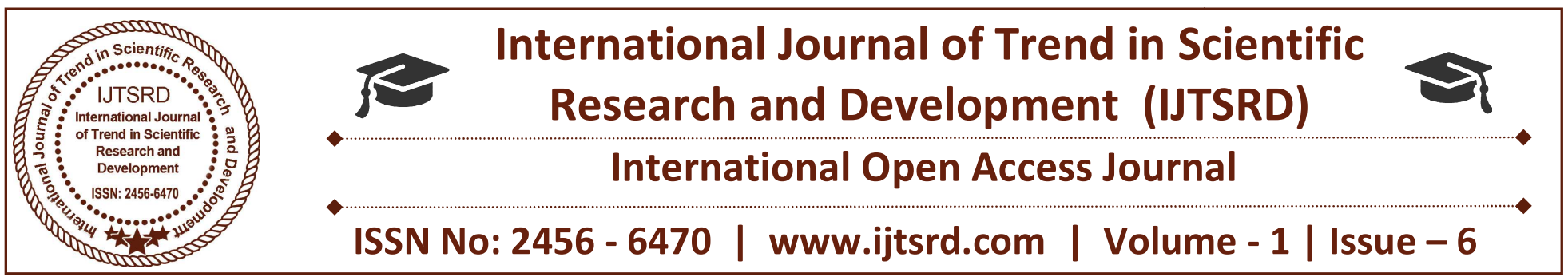

\title{
Solar Passive Architecture an Overview
}

\author{
Gayatri Hada \\ Asst. Professor, CE Department \\ Maharishi Arvind International Institute Of Technology, \\ Kota, Rajasthan, India
}

\section{ABSTRACT}

Basic requirement of shelter includes the use of enormous amount of energy for increasing population. Per capita electricity consumption has reached 1010 kilowatt-hour (kWh) in 2014-15, compared with 957 $\mathrm{kWh}$ in 2013-14 and 914.41 kWh in 2012-13, according to the Central Electricity Authority (CEA). India presently has an installed power generation capacity of $281,423 \mathrm{MW}$. The peak power deficit-shortfall in supply of power when the demand is maximum-was 5.2\% in year 2013-14. Electricity demand in India is very high due to population of 121 crores. Production of electricity is mainly done by fossil fuels. They release gasses and particulates when they burn. Gasses are usually invisible, and include carbon dioxide, which has impacts on the global environment by accelerating global warming. Other gasses, like carbon monoxide, have impacts within the home, by affecting breathing and reducing the oxygen content of the blood. Fossil fuels are depleting at a very fast rate and the production of electricity by them is not eco-friendly. For sustainable development and to reduce the environmental pollution Solar Passive Architecture is best option specially for building sector. Solar energy is genesis for all forms of energy. With its pollution free nature, virtually inexhaustible supply and global distribution- solar energy is very attractive energy resource. Making a building comfortable for human occupation with the minimum use of electricity consumption is called the Solar Passive Architecture.
Keywords: Passive heating, Sunspace, Thermal storage, Energy efficient design

\section{INTRODUCTION}

Passive Solar Architecture is a way of designing buildings that takes advantage of the benefits of the local environment (such as sunlight), while minimizing the adverse impacts of the climate (such as cold night time temperatures) on the comfort level of the building. Passive solar design integrates a combination of building features to reduce or even eliminate the need for mechanical cooling and heating and daytime artificial lighting. The side of the building that is utilized for solar gain needs to be facing the south to take maximum advantage of the sun's radiation. A passive solar building will simply passively sit, where it is located and be efficient for its design. Passive design home does collect, store and distribute heat in different ways- radiation, conduction and convection. Passive solar design is not new. In fact, ancient civilizations used passive solar design. What is new are building materials, methods, and solar positioning considerations. The aim of a passive solar building is to absorb (in winter) the maximum amount of radiation from the sun during the day, and to utilize this heat to warm the interior. The sides of the buildings exposed to the sun gain heat during the day, while the other sides, in the shade, lose heat. This helps to avoid overheating during the summer. 


\section{Objectives}

1. To promote energy efficient building design

2. To maximize use of renewable and natural resources in building

3. Building construction with optimum use of solar energy

4. Thermal comfort for the inhabitants

5. To reduce maintenance cost.

\section{PASSIVE SOLAR TECHNIQUES \\ HEATING}

They generally fall into one of the three categories: Direct gain, indirect gain, and isolated gain.

A. Direct Gain: is solar radiation that directly penetrates and is stored in the living space. Maximize solar heat gain in winter and minimize it in summer. Specific techniques include:

Start by using energy-efficient design strategies.

Orient the house with the long axis running east/west.

$>$ Select, orient, and size glass to optimize winter heat gain and minimize summer heat gain for the specific climate. Consider selecting different glazing for different sides of the house (exposures).

$>$ Size south-facing overhangs to shade windows in summer and allow solar gain in winter.

$>$ Add thermal mass in walls or floors for heat storage.

$>$ Use natural ventilation to reduce or eliminate cooling needs.

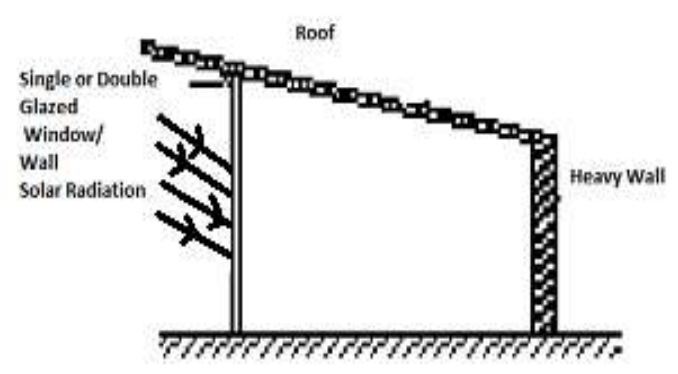

Hesvy Bare Floor

Fig 1:
Indirect Gain: collects, stores, and distributes solar radiation using some thermal storage material (e.g., Trombé wall). The wall consists of an 200 to $400 \mathrm{~mm}$ thick masonry wall on the south side of a house. A single or double layer of glass mounted about $25 \mathrm{~mm}$ or less in front of the dark-colored wall absorbs solar heat, which is stored in the wall's mass. The heat migrates through the wall and radiates into the living space. Heat travels through a masonry wall at an average rate of one inch per hour, so the heat absorbed on the outside of an 8-inch thick concrete wall at noon will enter the interior living space around 8 p.m.

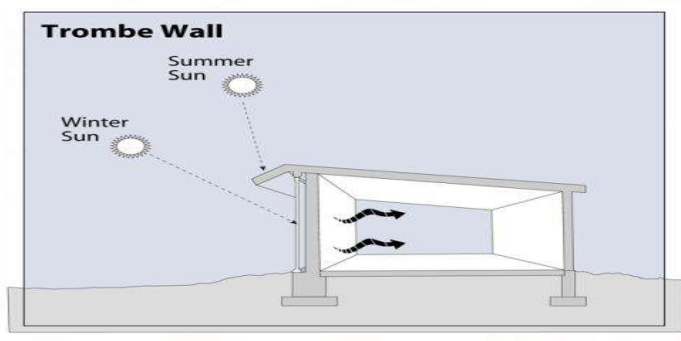

Fig 2:

\section{B. Isolated Gain (Sunspaces)}

The most common isolated-gain passive solar home design is a sunspace that can be closed off from the house with doors, windows, and other operable openings. Also known as a sunroom, solar room, or solarium, a sunspace can be included in a new home design or added to an existing home.

Sunspaces serve three main functions -- they provide auxiliary heat, a sunny space to grow plants, and a pleasant living area. The design considerations for these three functions are very different, and accommodating all three functions requires compromises.

\section{TABLE I HEAT LOAD ON SURFACES IN DifFERENT Climates}

\begin{tabular}{|l|l|l|l|l|l|}
\multicolumn{7}{|c|}{ Roof } & $\begin{array}{l}\text { North } \\
(\%)\end{array}$ & $\begin{array}{l}\text { South } \\
(\%)\end{array}$ & $\begin{array}{l}\text { East } \\
(\%)\end{array}$ & $\begin{array}{l}\text { West } \\
(\%)\end{array}$ \\
\hline Summer & $\begin{array}{l}48- \\
51\end{array}$ & $6-13$ & $0-2$ & $19-20$ & $19-20$ \\
\hline Winter & $\begin{array}{l}28- \\
34\end{array}$ & 0 & $35-44$ & $14-15$ & $14-15$ \\
\hline
\end{tabular}

The Ministry of New and Renewable Energy (MNRE) is the nodal Ministry of the Government of India for 
all matters relating to new and renewable energy sources. The broad aim of the Ministry is to develop and deploy new and renewable energy as a significant source in furtherance of the national aim of energy security and energy independence. It has been implementing broad-spectrum programmes covering more or less the entire range of new and renewable energy. These programmes broadly seek to supplement conventional fossil-fuel-based power through harnessing wind, solar, small hydro and bio power: take renewable energy systems to remote rural areas for lighting, cooking and motive power; use renewable energy in urban, industrial and commercial application; and develop alternate fuels and application for stationery, portable and transport uses apart from supporting research, design and development of new and renewable energy technologies, products and services.

\section{HOW PASSIVE SOLAR HOME WORKS}

\section{TABLE II}

Sunlight (10am to 5 pm)
enters south facing windows
and strikes the thermal mass
inside the home. The
sunlight converted to heat
energy, which heats both the
air and thermal mass
materials. It maintains
comfort during mid morning
to late afternoon periods.

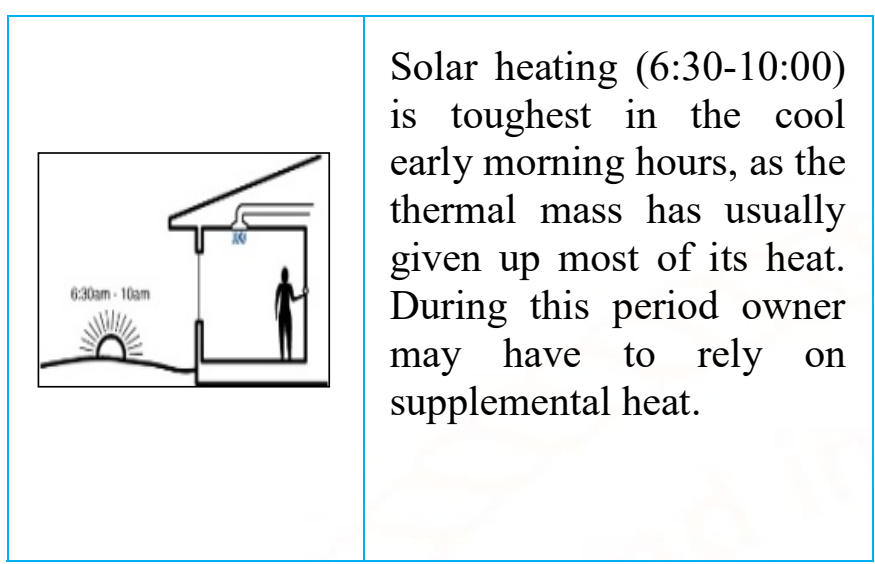

IV. HEAT STORAGE MATERIALS

A number of materials will work as storage media generally recommended are--rock, water (or waterantifreeze mixtures) and a phase-change chemical substance called Glauber's salt. These are the materials that most consistently meet the criteria for selecting a storage medium--namely, the ability (1) to deliver heat to its application points at a desirable temperature, and (2) to do it cheaply, based not so much on cost of the material as on cost of the total system and its maintenance.

\section{A. Rocks}

As a storage material, rocks are cheap and readily available, have good heat transfer characteristics with air (the transfer medium) at low velocities, and act as their own heat exchanger. Main disadvantages are their high volume-per-BTUstored ratio compared to water and phase-change materials (which means a bigger heat storage area), and difficulties with water condensation and microbial activity. If the dew point of the air coming into the storage is higher than the rock temperature, the moisture in the air condenses on the rocks. Moisture and heat in the rock bed can lead to microbial growth. Rock storage is the most reliable of the three storage systems because of its simplicity. Once the system is installed, maintenance is minimal and few things can decrease the performance of the storage.

Air solar collectors are usually used with rock storage devices. Since air collectors are cheaper and more maintenance-free than liquid collectors, a system using rock storage and air solar collectors seems the most logical for residential heating

\section{B. Water}

Water as a storage material has the advantages of being inexpensive and readily available, of having 
excellent heat transfer characteristics, and of being compatible with existing hot water systems. Its major drawbacks include difficulties with system corrosion and leakage, and more expensive construction costs.

Because of the good heat-storage-to-volume ratio (five times greater than rock) and greater efficiency of liquid solar collectors, liquid collection and storage systems can be very practical: (1) where close maintenance is available (such as in multipleresidence or industrial buildings), (2) where the ultimate use is hot water (such as in a dairy barn or food processing facility), or (3) where the water storage system can be directly coupled with an existing heating system as in residential hot water baseboard heat.

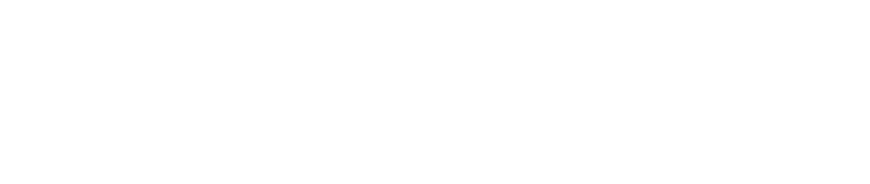

Fig 3: Comparative volumes for the same amount of heat storage using three different storage materials.

\section{Phase-Change Materials (PCM's)}

The phase-change material Glauber's salt, because of its low ratio of volume-per-BTU-stored, requires only $1 / 8$ the space of rocks and $2 / 5$ the space of water for comparable heat storage (see Figure 1). It also absorbs and releases most of its heat at a constant temperature. Disadvantages of Glauber's salt, at this point at least, are its cost relative to rock and water, and various technical problems (e.g., packaging problems due to its poor thermal conductivity and its corrosive nature).

\section{BASIC ELEMENTS FOR PASSIVE SOLAR HOME DESIGN :}

A. Properly Oriented Windows: Typically, windows or other devices that collect solar energy should face within 30 degrees of true south and should not be shaded during the heating season by other buildings or trees from 9 a.m. to 3 p.m. each day. During the spring, fall, and cooling season, the windows should be shaded to avoid overheating.
B. Thermal Mass. Thermal mass in a passive solar home -- commonly concrete, brick, stone, and tile -- absorbs heat from sunlight during the heating season and absorbs heat from warm air in the house during the cooling season. Other thermal mass materials such as water and phase change products are more efficient at storing heat, but masonry has the advantage of doing

Double duty as a structural and/or finish material. In well-insulated homes in moderate climates, the thermal mass inherent in home furnishings and drywall may be sufficient, eliminating the need for additional thermal storage materials.

C. Distribution Mechanisms: Solar heat is transferred from where it is collected and stored to different areas of the house by conduction, convection, and radiation. In some homes, small fans and blowers help distribute heat. Conduction occurs when heat moves between two objects that are in direct contact with each other, such as when a sun-heated floor warms your bare feet. Convection is heat transfer through a fluid such as air or water, and passive solar homes often use convection to move air from warmer areas -- a sunspace, for example -- into the rest of the house. Radiation is what you feel when you stand next to a wood stove or a sunny window and feel its warmth on your skin. Darker colors absorb more heat than lighter colors, and are a better choice for thermal mass in passive solar homes.

D. Control strategies: Properly sized roof overhangs can provide shade to vertical south windows during summer months. Other control approaches include electronic sensing devices, such as a differential thermostat that signals a fan to turn on; operable vents and dampers that allow or restrict heat flow; low-emissivity blinds; operable insulating shutters; and awnings.

\section{CONCLUSION}

In India, solar energy appears to be gaining some momentum, as a result of a few key factors, i.e., a large number of benefits accruing from usage of solar power.

The idea of passive solar heating is simple, but using it effectively can require precisely configuring parts of your home to take advantage of the angle of the 
sun. Properly designed overhangs can let in welcome warmth in the winter months and block the sun's heat in the summer. There are several advantages of passive heating such as

1) Monetary Savings- A 14\% reduction in monthly energy costs can result. This can be reduced to nearly $47 \%$, if the home is properly insulated. Additionally, all heating, cooling and lighting generated by this system is utility bill free.

2) No Equipment or Appliances Required Although some may use fans, ducts or blowers to move heat from one place to another, you can create a venting system that uses the natural properties of rising heat with clerestory windows.

3) No Fossil Fuels needed - Unless you need to use a fossil fuel driven supplement, but this is not required.

4) Environmental Benefits: It is a completely clean energy source and produces no harmful fumes, pollutants or emissions. Not every region of the country receives enough sustained sunlight to make solar heating a good option. In northern climates, the harsh winters can overwhelm a passive solar heating system, making supplemental heating a must to keep your home at a comfortable temperature.

\section{REFERENCES}

[1] N. K. Bansal, G. Hauser and G. Minke, "Passive Building Design, A Handbook of Natural Climate Control", Elsevier, Amsterdam, 1994.

[2] N. K. Bansal and G. Minke, "Climate Zones and Rural Housing in India”, KFA, Germany, 1995.

[3] M. S. Bhandari, "Thermal analysis of buildings through Simulation Models, PhD Thesis, Centre for Energy Studies", IIT, Delhi, Hauz Khas, New Delhi, India, 1995.

[4] www.nmsea.org/Passive_Solar/Passive_Solar_De sign.htm + passive + heating + solar\&hl $=\operatorname{tr}$

[5] http://www.consumerenergycenter.org/homeandw ork/homes/construction/solardesign/insulation.htm 1

[6] http://www.greenbuilder.com/sourcebook/PassSol Guide1-2.html

[7] www.mnre.gov.in

[8] http://www.eere.energy.gov/consumerinfo/factshe ets/passive_solar.html 